\title{
Annealing and Mechanical Properties of Bulk Y-Ba-Cu-O*
}

K. C. Goretta, P. Diko,** Ming Jiang, M. M. Cuber

Argonne National Laboratory, Argonne, IL, USA

\author{
Ming $\mathrm{Xu} * * *$ \\ University of Chicago, Chicago, $\mathbb{L}$, USA
}

J. E. Ostenson

Ames Laboratory, Ames, IA, USA

S. Sengupta
Superconductive Components, Inc., Columbus, OH, USA
August 1998
SEP 21 1993
The submitted manuscript has been created by the

Paper submitted to 1998 Applied Superconductivity Conference, September 13-18, 1998, Palm Desert, CA; IEEE Transactions on Applied Superconductivity.

*Work supported by the U.S. Department of Energy (DOE), Office of Energy Efficiency and Renewable Energy, as part of a DOE program to develop electric power technology, under Contract W-31-109-Eng-38, and Office of International Technology Cooperation under Project 004-095; the Slovak Academy of Sciences (Project No. 2/1323/94); a Fulbright Grant for P.D. administrated by the U.S. Information Agency with cooperation of the Council for International Exchange of Scholars; the U.S.--Slovak Science and Technology Joint Fund in cooperation with the Slovak Agency for Strategy of Society, Science and Technology; and at Ames Laboratory, Iowa State University, by the Director for Energy Research, the DOE Office of Basic Sciences, under Contract W-7405-ENG-82.

**Permanent address: Institute of Experimental Physics, Slovak Academy of Sciences, Kosice, Slovakia.

***Current address: Lucent Technologies, Naperville, IL, USA. 


\section{DISCLAIMER}

This report was prepared as an account of work sponsored by an agency of the United States Government. Neither the United States Government nor any agency thereof, nor any of their employees, make any warranty, express or implied, or assumes any legal liability or responsibility for the accuracy, completeness, or usefulness of any information, apparatus, product, or process disclosed, or represents that its use would not infringe privately owned rights. Reference herein to any specific commercial product, process, or service by trade name, trademark, manufacturer, or otherwise does not necessarily constitute or imply its endorsement, recommendation, or favoring by the United States Government or any agency thereof. The views and opinions of authors expressed herein do not necessarily state or reflect those of the United States Government or any agency thereof. 


\section{DISCLAIMER}

Portions of this document may be illegible in electronic image products. Images are produced from the best available original document. 


\title{
Annealing and Mechanical Properties of Bulk Y-Ba-Cu-O
}

\author{
K. C. Goretta, P. Diko,* Ming Jiang, M. M. Cuber \\ Argonne National Laboratory, Argonne, IL, USA \\ Ming $\mathrm{Xu}^{* *}$ \\ University of Chicago, Chicago, IL, USA \\ J. E. Ostenson \\ Ames Laboratory, Ames, IA, USA \\ S. Sengupta \\ Superconductive Components, Inc., Columbus, $\mathrm{OH}$, USA
}

\section{Footnote:}

Manuscript received September 14, 1998.

This work was supported by the U.S. Department of Energy (DOE), Office of Energy Efficiency and Renewable Energy, as part of a DOE program to develop electric power technology, under Contract W-31-109-Eng-38, and Office of International Technology Cooperation under Project 004-095; the Slovak Academy of Sciences (Project No. 2/1323/94); a Fulbright Grant for P.D. administrated by the U.S. Information Agency with cooperation of the Council for International Exchange of Scholars; the U.S.-Slovak Science and Technology Joint Fund in cooperation with the Slovak Agency for Strategy of Society, Science and Technology; and at Ames Laboratory, Iowa State University, by the Director for Energy Research, the DOE Office of Basic Sciences, under Contract W-7405-ENG-82.

*Permanent address: Institute of Experimental Physics, Slovak Academy of Sciences, Kosice, Slovakia.

**Current address: Lucent Technologies, Naperville, IL, USA.

Abstract-Single-domain melt-processed $\mathrm{YBa}_{2} \mathrm{Cu}_{3} \mathrm{O}_{\mathrm{x}} / \mathrm{Y}_{2} \mathrm{BaCuO}_{5}$ and conventional polycrystalline sintered $\mathrm{YBa}_{2} \mathrm{Cu}_{3} \mathrm{O}_{x}$ pellets were prepared. Elastic modulus, hardness, and fracture strength were measured on selected sections cut from the pellets. Strength in the meltprocessed pellets ranged from 32 to $94 \mathrm{MPa}$ and was highest in the center. Variations in strength were related to microstructural features, especially $\mathrm{Y}_{2} \mathrm{BaCuO}_{5}$ distribution. To 
improve strength, we attempted to minimize microcracking by manipulating cooling rates, annealing times, and oxygen partial pressure. Extent of cracking was evaluated by electron microscopy and change in elastic modulus and strength. We found that control of annealing reduced microcracking of the polycrystalline sintered pellets, but had little effect on the singledomain melt-processed pellets.

\section{INTRODUCTION}

Bulk melt-processed $\mathrm{YBa}_{2} \mathrm{Cu}_{3} \mathrm{O}_{\mathrm{x}} / \mathrm{Y}_{2} \mathrm{BaCuO}_{5}(\mathrm{Y} 123 / \mathrm{Y} 211)$ superconductors are being developed for many applications [1]-[3]. In most applications, magnetic fields will be high, and resultant mechanical stresses can be sufficiently large to induce gross fracturing of the superconductor [4]. It may well be that mechanical considerations surpass superconducting ones in designing components.

The microstructures of melt-processed Y123/Y211 materials, including the so-called single-domain materials, are complex. Subgrain boundaries, Y211 gradients, and retained phases from the melt are common [1]-[9]. Although much has been written about the basic mechanical properties of sintered and melt-processed Y123 [10]-[20], little emphasis has been placed on mechanical properties with respect to variations in local microstructure or processing. We undertook this work with two goals in mind: (a) to relate strength with microstructure and position in melt-processed Y123/Y211 compacts and (b) to determine whether strength could be improved through heat treatment. We used a combination of elastic modulus, hardness, and strength measurements to evaluate local mechanical properties, but found that not all measurements yielded meaningful data for all samples.

\section{EXPERIMENTAL DETAIIS}

For the $\mathrm{Y} 123 / \mathrm{Y} 211$ compacts, a mixture of composition $\approx 74$ wt.\% Y123, 25 wt.\% Y211, and $\mathrm{L}$ wt.\% $\mathrm{PtO}_{2}$ was prepared by ball-milling. Hexagonal pellets were cold-pressed in a 29mm-wide die and melt-processed in air by conventional means. A NdBaCuO single-crystal 
seed was placed on the center of the top surface of each pellet to promote single-domain growth [2]. To compare microstructure and properties, unalloyed Y123 pellets that were $\approx 10$ $\mathrm{mm}$ in diameter and $3 \mathrm{~mm}$ thick were prepared by cold-pressing and sintering in $\mathrm{O}_{2}$ at $980^{\circ} \mathrm{C}$

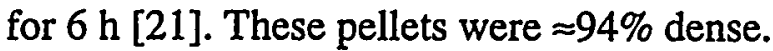

Specimens for mechanical studies were generally cooled in $\mathrm{N}_{2}$. (We used air and $\mathrm{O}_{2}$, but found that initial cooling in $\mathrm{N}_{2}$ proved to be better for optimizing mechanical properties.) The specimens were annealed by one of two schedules: either heated in $\mathrm{O}_{2}$ to $\approx 450^{\circ} \mathrm{C}$ and held for an extended period; or heated in $\mathrm{N}_{2}$ to $\approx 720^{\circ} \mathrm{C}$, and then annealed stepwise in $\mathrm{O}_{2}$ (Fig. 1). It has been shown that the time required to anneal Y123 can be reduced by using such stages, because chemical diffusion of oxygen increases with the oxygen content of Y123 [22]-[24]. The steps shown in Fig. 1 were designed to take advantage of the more-rapid oxygenation kinetics and to minimize microcracking in the specimens. We thought that by increasing the oxygen content slowly, and thus changing the lattice parameters of the Y123 gradually, cracking might be minimized. We were careful to cool the specimens slowly through the tetragonal-to-orthorhombic phase transformation because the transformation induces large displacements [25].

Fig. 1. Basic annealing schedules for sintered Y123 pellets. Melt-processed compacts were processed similarly, except that the total time at temperature was as long as $\approx 120 \mathrm{~h}$, depending on specimen thickness.

Microstructures were examined by optical microscopy and scanning electron microscopy (SEM). Young's modulus (E) was obtained ultrasonically with a Panametrics Model 5600 Ultrasonic Analyzer (Waltham, MA). Vickers hardness was measured with a 5-N load on a Leco Hardness Tester (St. Joseph, MI). Strengths of small bars that were cut from the meltprocessed compacts with a slow-speed diamond saw were measured in four-point bending on an Instron Model 4505 Universal Tester (Canton, MA). Each bar was $\approx 3 \times 3 \times 20 \mathrm{~mm}$. For half of the bars, the tensile surface was parallel to the c-axis of the compact; for the other half, the tensile surface was perpendicular to the c-axis. 


\section{RESULTS AND DISCUSSION}

\section{A. Microstructures}

Although the melt-processed Y123/Y211 compacts were nominally single domain, they exhibited subgrain boundaries caused by growth along two types of fronts: $\mathrm{c}$-axis growth below the single-crystal seed and a-axis growth from the four sides of the seed (Figs. 2a and b). More important, the distribution of Y211 particles in the compacts was not homogeneous. The three types of inhomogeneities that were observed have been discussed in detail previously [8]. We will briefly summarize the Y211 observations.

The most prominent inhomogeneity was an increase in Y211 density along the c-growth direction. This inhomogeneity has been quantified as the dependence of Y211 volume fraction on the radial distance from the boundary with the central domain [8]. Results are shown schematically in Fig. 2c. The second Y211 inhomogeneity developed at $90^{\circ}$ subgrain boundaries between a- and c-axis growth fronts. Bands of higher Y211 concentration ran across both sides of the boundaries (Fig. 3). The third observed inhomogeneity was an oscillation of Y211 concentration perpendicular to the c-direction of the compact. This inhomogeneity was the least significant of the three; it has been related to slight fluctuations in growth rate [8].

Fig. 2 Schematic diagram of (a) and (b) crystal growth directions, and (c) Y211 distributions in single-domain $\mathrm{Y} 123 / \mathrm{Y} 211$ compacts.

Fig. 3. Optical photomicrographs showing Y211 concentrations within melt-processed compact: (a) region beneath the seed, (b) c-growth region near compact perimeter, and (c) bands of higher Y211 concentration along inner side of a-c subgrain boundaries (Y211 oscillations parallel to $a-b$ plane can also be observed). 
The microstructure of the sintered Y123 pellets consisted of randomly oriented grains. The largest grains were $\approx 10 \mu \mathrm{m}$ in maximum dimension and exhibited aspect ratios of $\approx 3$. When viewed optically in polarized light, twin structures were uniform and fine in both the melt-processed compacts and the sintered pellets that were annealed with the ramped cooling schedule. Larger twin features were evident for specimens annealed at $450^{\circ} \mathrm{C}$ only (Fig. 4).

Fig. 4. Optical photomicrograph in polarized light of sintered $Y 123$ pellets annealed (a) in stages and (b) isothermally at $450^{\circ} \mathrm{C}$; a coarser twin structure is apparent in (b).

\section{B. Mechanical properties}

We attempted three types of measurements, ranging from more to less intrinsic. Elastic modulus and hardness are relatively insensitive to small concentrations of second phases or microcracks, whereas fracture strength is highly sensitive to flaw population.

Good ultrasonic signals were obtained for the sintered Y123 pellets, but not for the meltprocessed Y123/Y211 compacts. Scattering from second phases and cracks was too severe in the latter. We found that the annealing schedule profoundly affected the value of $E$ for the sintered Y123. Pellets annealed in stages from 720 to $450^{\circ} \mathrm{C}$ exhibited an $\mathrm{E}$ of $101 \pm 4 \mathrm{GPa}$; pellets annealed at $450^{\circ} \mathrm{C}$ exhibited an $\mathrm{E}$ of $81 \pm 3 \mathrm{GPa}$. Thus, our supposition that slow cooling may improve mechanical properties may be correct, at least for some specimens. This improvement was correlated with the more-uniform twin structures, and probably reduced microcracking, in the Y123 pellets that were annealed in stages. It is well known that stress affects twin structures [12]-[27]. $\left(T_{c}\right.$ values were independent of annealing; transitions were sharp at 91-92 $\mathrm{K}$ for all specimens.)

We did not measure the strengths of the Y123 pellets because we believed that such measurements would reflect specimen preparation rather than inherent properties. For the meltprocessed compacts, however, hardness and strength were the only properties that could be measured reliably. Hardness depended on whether the indentation was parallel or perpendicular

$$
5
$$


to the c-axis of the compact. Hardness also exhibited a pattern with respect to location, but not with respect to annealing schedule. The Vickers hardness results are summarized below:

1. Hardness was generally $\approx 20 \%$ higher when measured perpendicular to the $c$-axis rather than parallel to the c-axis.

2. The minimum hardness of 3.3-3.7 GPa was found beneath the seed.

3. The maximum hardness of 5.4-6.1 GPa was found a few millimeters from the rim, near the top of the compact.

4. In the bottom halves of the compacts, the hardness was 4.2-5.3 GPa, regardless of position.

Thus, low Vickers hardnesses correlated with low concentrations of the Y211 phase. We attempted to estimate fracture toughness from cracks that emanated from the corners of the hardness impressions [14]-[18]; however, the cracks tended to follow crystallographic planes and were strongly influenced by defects. No reliable fracture-toughness data could be obtained.

Identifying the strength distribution and improving overall strength were the primary goals of this work. Half of these goals were met. Strength was not significantly affected by whether the tensile surface of the bend bars was parallel or perpendicular to the c-axis or whether the specimens were annealed in stages or isothermally. Average strength values with position are shown in Fig. 5; three to five bars were measured per location and radial symmetry was assumed.

Fig. 5. Schematic diagram of positions of bending bars, and corresponding flexural strengths in Mpa for $\mathrm{Y} 123 / \mathrm{Y} 211$ compacts.

The strength values are similar to those reported for melt-processed $\mathrm{Y} 123$, including compacts that contain $\mathrm{Ag}$ for strength improvement [28]. In general, highest strengths were in the center, in regions of relatively less $Y 211$, and the tops of compacts were stronger than the bottoms. The fact that strength could not be improved through annealing is perhaps not surprising. Cracks tend to form at Y211 particles during cooling because of differences in thermal expansion between Y123 and Y211 [7]-[9]. Although Y211 within a Y123 matrix can 
lead to improved fracture toughness [11],[13], strength does not follow suit because of the introduction of a new population of significant flaws.

Y211 within Y123 grains is necessary for optimal superconducting properties. However, our results agree with those of others [6]-[9] for the adverse effects of Y211 on strength. Furthermore, the strength of melt-processed Y123/Y211 compacts is rather low, irrespective of position. We conclude that a composite scheme may be needed to increase the strength of melt-processed compacts to that needed for a given high-field application. Oxygen content influences levitation properties and strength [21],[29]-[31], but for large-grained meltprocessed compacts, the rate at which oxygen is introduced has little effect on mechanical strength.

\section{SUMMARY}

Single-domain Y123/Y211 compacts exhibited a complex microstructure that featured significant gradients of $\mathrm{Y} 211$. These compacts were hardest where the Y211 concentrations tended to be high, but were strongest in flexure where the Y211 concentration was low. The strength range was 32-94 MPa, which may be low with respect to requirements of many applications. Oxygen annealing in stages leads to reduced total annealing times, and for sintered Y123 specimens, it led to increases in stiffness, probably because of reduced microcracking. However, annealing in stages had no appreciable effect on strength of the Y123/Y211 compacts, probably because microcracking was dominated by the Y211 particles.

\section{REFERENCES}

[1] N. McN. Alford, T. W. Button, and J. D. Birchall, "Processing, properties and devices in high- $\mathrm{T}_{\mathrm{c}}$ superconductors," Supercond. Sci. Technol., vol. 3, pp. 1-7, 1990.

[2] K. Salama and D. F. Lee, "Progress in melt texturing of $\mathrm{YBa}_{2} \mathrm{Cu}_{3} \mathrm{O}_{\mathrm{x}}$ superconductor," Supercond. Sci. Technol., vol. 7, pp. 177-193, 1994. 
[3] S. Sengupta, J. Corpus, M. Agarwal, and J. R. Gaines Jr., "Feasibility of manufacturing large domain YBCO levitators by using melt processing techniques," Mater. Sci. Eng., vol. B53, pp. 62-65, 1998.

[4] V. V. Chabanenko, A. I. D'yachenko, H. Szymczak, and S. Piechota, "Failure of textured YBaCuO samples in the strong magnetic field," Physica C, vol. 289, pp. 211215, 1997.

[5] A. T. Rowley, R. Wroe, A. Vazquez-Navarro, W. Lo, and D. A. Cardwell, "Microwave-assisted oxygenation of melt-processed $\mathrm{YBa}_{2} \mathrm{Cu}_{3} \mathrm{O}_{7-\partial}$ ceramics," J. Mater. Sci., vol. 32, pp. 4541-4547, 1997.

[6] P. Diko, W. Gowalek, T. Habisreuther, T. Klupsch, and P. Görner, "Macro- and microcracking, subgrains, twins and thermal stresses in $\mathrm{YBa}_{2} \mathrm{Cu}_{3} \mathrm{O}_{7-\mathrm{x}}(123)-\mathrm{Y}_{2} \mathrm{BaCuO}_{5}$ (211) melt-textured superconductors studied by means of polarized light microscopy," $J$. Microscopy, vol. 184, pp. 46-57, 1996.

[7] P. Diko, "Thermal stresses and microcracking caused by 211 particles in $\mathrm{Y}-\mathrm{Ba}-\mathrm{Cu}-\mathrm{O}$ melt-processed bulks," Mater. Sci. Eng., vol. B53, pp. 149-153, 1998.

[8] P. Diko, V. R. Todt, D. J. Miller, and K. C. Goretta, "Domain structure and $\mathrm{Y}_{2} \mathrm{BaCuO}_{5}$ distribution in single- and multiple-domain melt-textured YBaCuO," Superlatt. Micro., vol. 21, pp. 403-413, 1997.

[9] P. Diko, "Cracking in melt-processed RE-Ba-Cu-O superconductors," Supercond. Sci. Technol., vol. 11, pp. 68-72, 1998.

[10] J. P. Singh, D. Shi, and D. W. Capone II, "Mechanical and superconducting properties of sintered composite $\mathrm{YBa}_{2} \mathrm{Cu}_{3} \mathrm{O}_{7-\partial}$ tape on a silver substrate," Appl. Phys. Lett., vol. 53, pp. 237-239, 1988.

[11] S. Ochiai, K. Osamura, and T. Takayama, "Fracture toughness measurements of $\mathrm{Ba}_{2} \mathrm{YCu}_{3} \mathrm{O}_{7-\mathrm{x}}$ superconducting oxide by means of indentation technique," Jpn. J. Appl. Phys., vol. 27, pp. L1101-L11-3, 1988.

[12] T. M. Shaw, S. L. Shinde, D. Dimos, R. F. Cook, P. R. Duncombe, and C. Kroll, "The effect of grain size on microstructure and stress relaxation on polycrystalline $\mathrm{YBa}_{2} \mathrm{Cu}_{3} \mathrm{O}_{7-\partial}$," J. Mater. Res., vol. 4, pp. 248-256, 1989. 
[13] H. Fujimoto, M. Murakami, T. Oyama, Y. Shiohara, N. Koshizuka, and S. Tanaka, "Fracture toughness of YBaCuO prepared by MPMG process," Jpn. J. Appl. Phys., vol. 29, pp. L1793-L1795, 1990.

[14] A. S. Raynes, S. W. Freiman, F. W. Gayle, and D. L. Kaiser, "Fracture toughness of $\mathrm{YBa}_{2} \mathrm{Cu}_{3} \mathrm{O}_{6+2}$, single crystals: anisotropy and twinning effects," J. Appl. Phys., vol. 70, pp. 5254-5257, 1991.

[15] J. P. Singh, R. A. Guttschow, J. T. Dusek, and R. B. Poeppel, "Role of $\mathrm{pO}_{2}$ in microstructural development and properties of $\mathrm{YBa}_{2} \mathrm{Cu}_{3} \mathrm{O}_{\mathrm{x}}$, superconductors," J. Mater. Res., vol. 7, pp. 2324-2328, 1992.

[16] H. Fujimoto, M. Murakami, and N. Koshizuka, "Effect of $\mathrm{Y}_{2} \mathrm{BaCuO}_{5}$ on fracture toughness of YBaCuO prepared by a MPMG process," Physica C, vol. 203, pp. 103$110,1992$.

[17] T. Oka, Y. Itoh, Y. Yanagi, H. Tanaka, S. Takashima, Y. Yamada, and U. Mizutani, "Critical current density and mechanical strength of $\mathrm{YBa}_{2} \mathrm{Cu}_{3} \mathrm{O}_{7-\partial}$ superconducting composites containing $\mathrm{Zr}, \mathrm{Ag}$ and $\mathrm{Y}_{2} \mathrm{BaCuO}_{5}$ dispersions by melt-processing," Physica C, vol. 200, pp. 55-64, 1992.

[18] A. Goyal, P. D. Funkenbusch, D. M. Kroeger, and S. J. Burns, "Anisotropic hardness and fracture toughness of highly aligned $\mathrm{YBa}_{2} \mathrm{Cu}_{3} \mathrm{O}_{7-\partial}$," J. Appl. Phys., vol. 71, pp. 2363-2367, 1992.

[19] N.-L. Wu, H. H. Zern, and C.-L. Chen, "Low-temperature melt growth of $\mathrm{YBa}_{2} \mathrm{Cu}_{3} \mathrm{O}_{7}$ x/silver composites in partial vacuum," Physica C, vol. 241, pp. 198-207, 1995.

[20] N.-L. Wu, C.-C. Hsu, and C.-H. Lee, "Reduced cracking in melt-grown $\mathrm{RBa}_{2} \mathrm{Cu}_{3} \mathrm{O}_{7}$ (R=Nd,Sm)/gold composites," Jpn. J. Appl. Phys., vol. 37, pp. L438-L440, 1998.

[21] K. C. Goretta, N. Chen, M. T. Lanagan, W. Wu, J. P. Singh, R. A. Olson, J. L. Routbort, and R. B. Poeppel, "Sintering and annealing of bulk high- $\mathrm{T}_{\mathrm{c}}$ superconductors $(\mathrm{Y}-\mathrm{Ba}-\mathrm{Cu}-\mathrm{O})$ to effective properties," Indust. Heat., vol. 60, pp. 40-43, February 1993.

[22] T. Matsui, K. Naito, and S. Hagino, "Oxygen nonstoichiometry and chemical diffusion coefficient of oxygen in $\mathrm{Ba}_{2} \mathrm{YCu}_{3} \mathrm{O}_{7-\mathrm{x}}$," in Non-stoichiometric Compounds Surfaces, 
Grain Boundaries and Structural Defects, J. Nowotny and W. Weppner, Eds., London: Kluwer, 1989, pp. 471-484.

[23] K. C. Goretta, R. B. Poeppel, D. Shi, N. Chen, S. J. Rothman, J. L. Routbort, and J. P. Stoessel, "Diffusion and processing of $\mathrm{YBa}_{2} \mathrm{Cu}_{3} \mathrm{O}_{\mathrm{x}}$," Ceram. Trans., vol. 13, pp. 369-379, 1990.

[24] S. Y. Seoul and Y. S. Cha, "Diffusion and cooling rate during annealing of sintered bulk $\mathrm{YBa}_{2} \mathrm{Cu}_{3} \mathrm{O}_{7-\mathrm{x}}, "$ Appl. Supercond., vol. 2, pp. 7-16, 1994.

[25] P. Diko, S. Takebayashi, and M. Murakami, "Origin of subgrain formation in meltgrown Y-Ba-Cu-O bulks," Physica C, vol. 97, pp. 216-222, 1998.

[26] T. Hashimoto, K. Fueki, A. Kishi, T. Azumi, and H. Koinuma, "Thermal expansion coefficients of high- $T_{c}$ superconductors," Jpn. J. Appl. Phys., vol. 27, pp. L214-L216, 1988.

[27] D. L. Kaiser, F. W. Gayle, R. S. Roth, and L. J. Schwartzendruber, "Thermomechanical detwinning of superconducting $\mathrm{YBa}_{2} \mathrm{Cu}_{3} \mathrm{O}_{7-\mathrm{x}}$ single crystals," $J$. Mater. Res., vol. 4, pp. 745-747, 1989.

[28] D. Lee and K. Salama, "Enhancements in current density and mechanical properties of Y-Ba-Cu-O/Ag composites,” Jpn. J. Appl. Phys., vol. 29, pp. L2017-L2019, 1990.

[29] D. Shi, D. Qu, and B. A. Tent, "Effect of oxygenation on levitation force in seeded melt grown single-domain $\mathrm{YBa}_{2} \mathrm{Cu}_{3} \mathrm{O}_{\mathrm{x}}$," Physica $C$, vol. 291, pp. 181-187, 1997.

[30] M. Watahiki, W.-J. Jang, S. Tajima, and M. Murakami, "Magnetic properties of $\mathrm{YBa}_{2} \mathrm{Cu}_{3} \mathrm{O}_{\mathrm{y}}$ crystal with various oxygen annealing conditions," J. Appl. Phys., vol. 83, pp. 377-381, 1998.

[31] C.-J. Kim, K.-B. Kim, I.-H. Kuk, G.-W. Hong, Y.-S. Lee, and H.-S. Park, "Microstructure change during oxygen annealing and the effect on the levitation force of melt-textured Y-Ba-Cu-O superconductors," Supercond. Sci. Technol., vol. 10, pp. 947-954, 1997. 


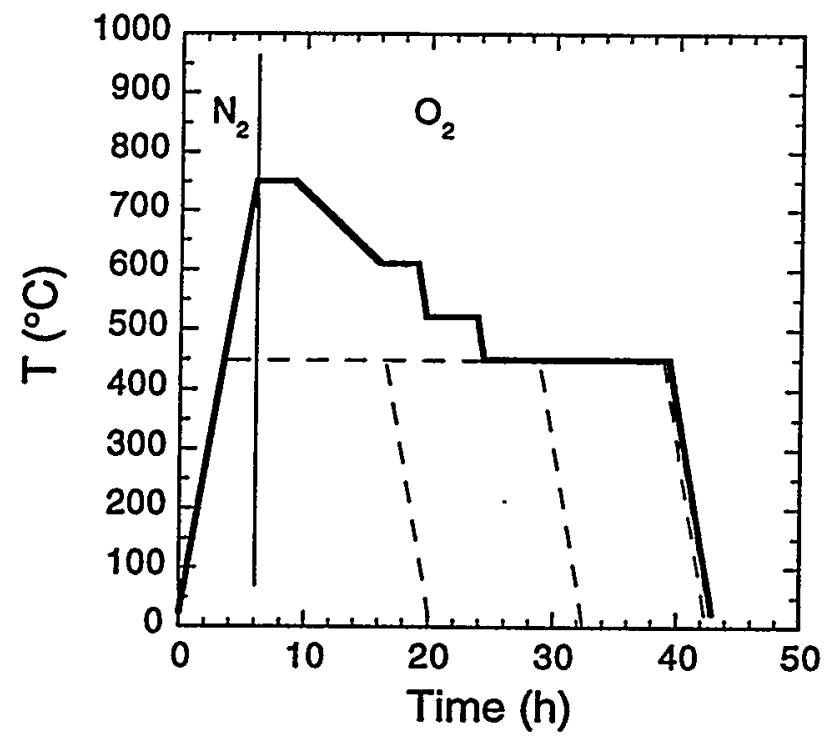

Fig. 1 


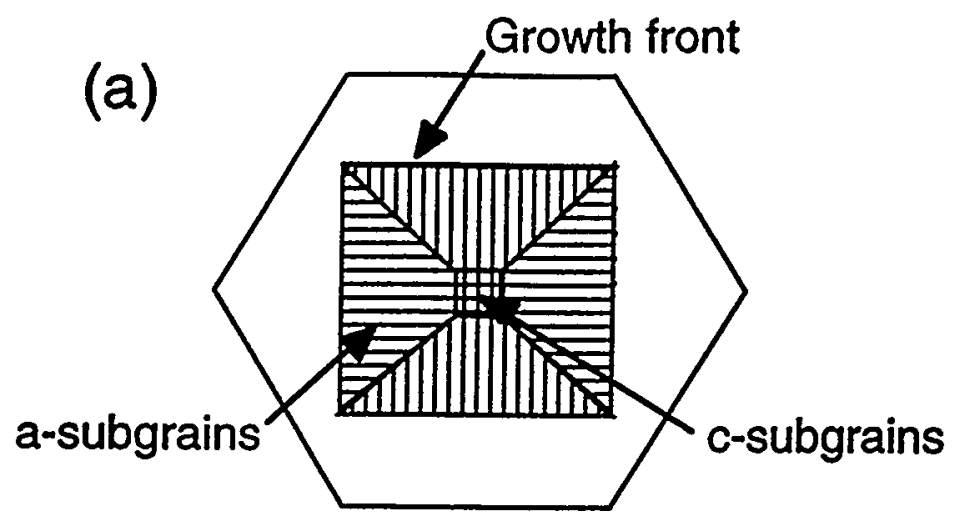

Fig. 2.

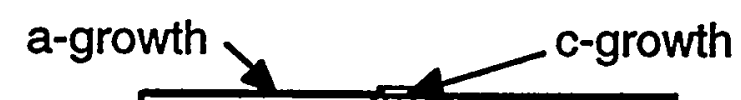

(b)

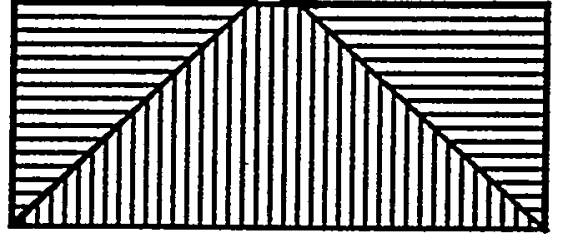

(c)

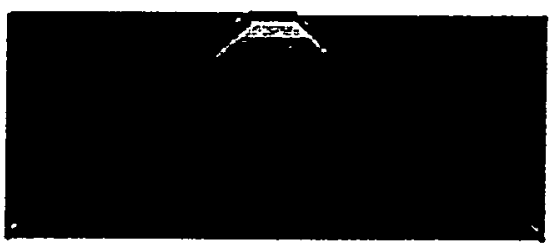



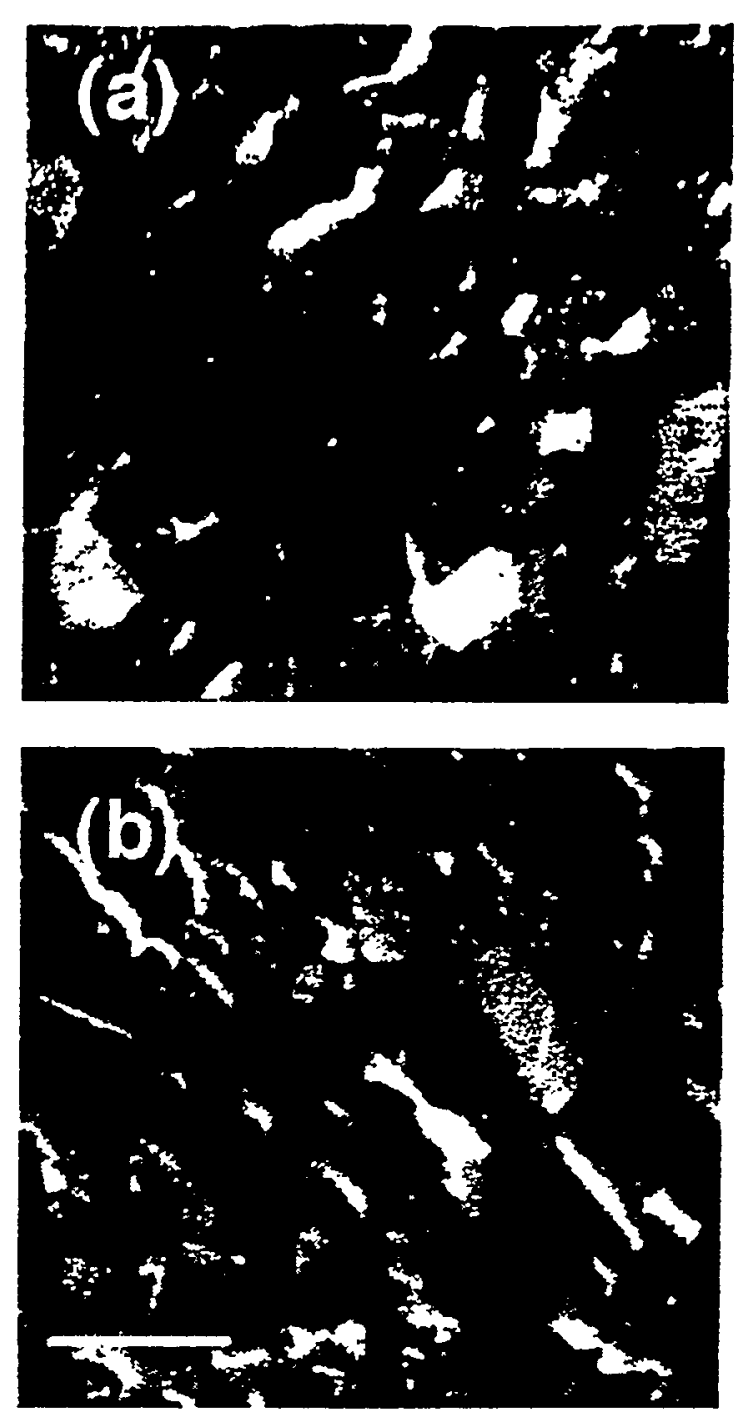

F.g. 3. 


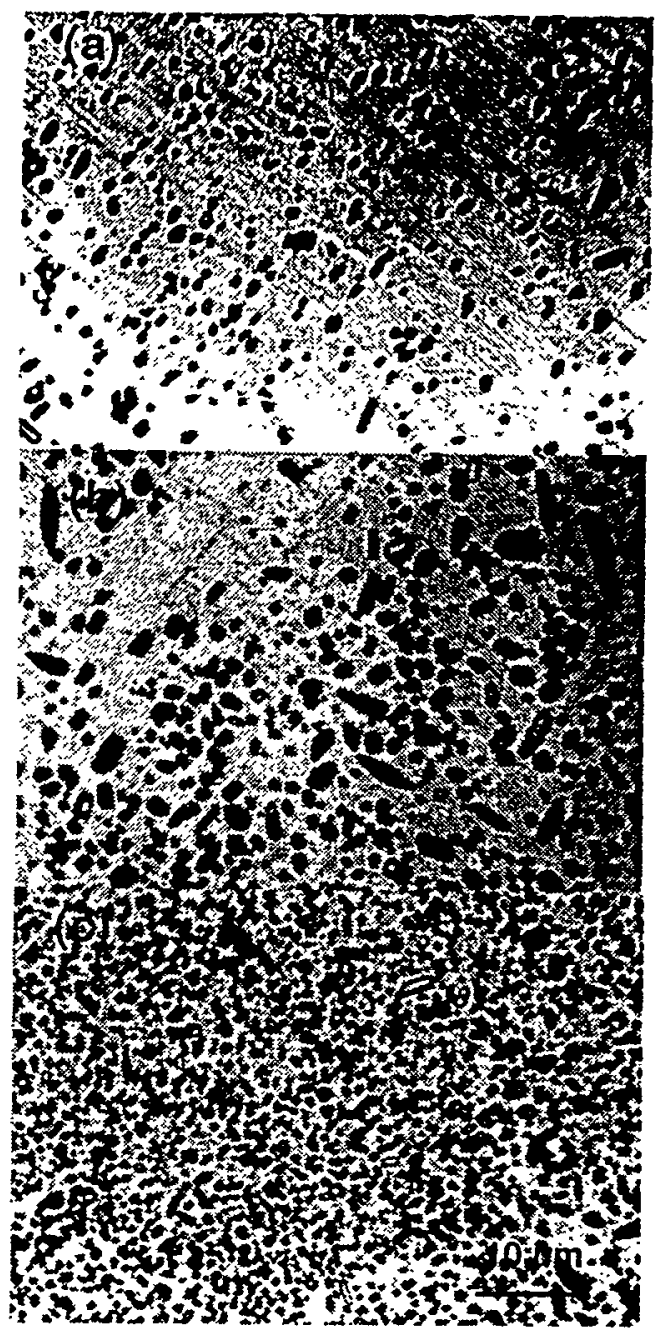



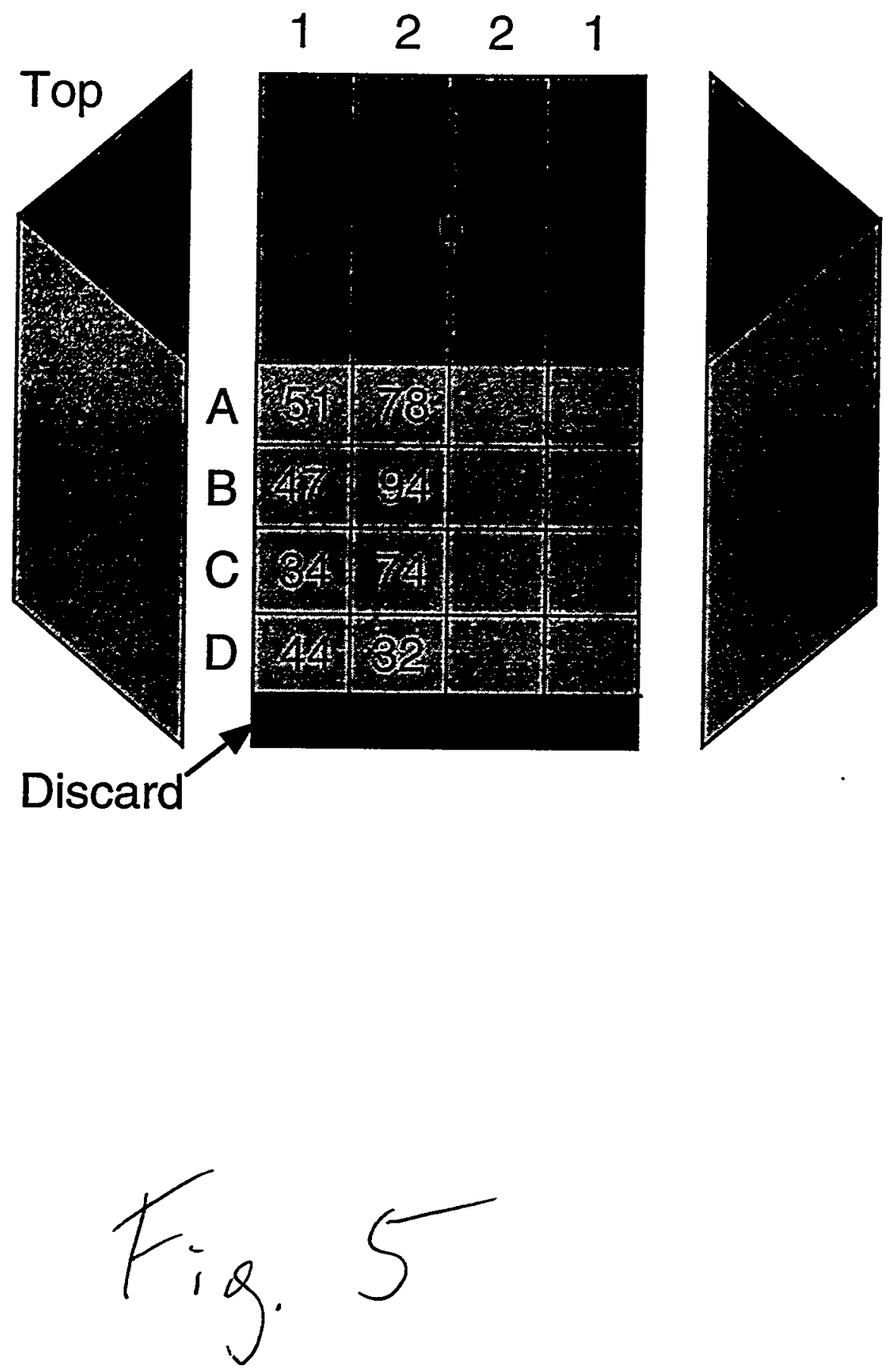